\title{
Cancer stem-like cell: a novel target for nasopharyngeal carcinoma therapy
}

Pingpin Wei ${ }^{1,2+}$, Man Niu ${ }^{1,2+}$, Suming Pan ${ }^{2,3}$, Yanhong Zhou ${ }^{1,2}$, Cijun Shuai ${ }^{4}$, Jing Wang ${ }^{1}$, Shuping Peng ${ }^{1,2^{*}}$ and Guiyuan $\mathrm{Li}^{1,2^{*}}$

\begin{abstract}
Nasopharyngeal carcinoma (NPC) is the most common cancer originating in the nasopharynx, and is extremely common in southern regions of China. Although the standard combination of radiotherapy and chemotherapy has improved the efficiency in patients with NPC, relapse and early metastasis are still the common causes of mortality. Cancer stem-like cells (CSCS) or tumor initial cells are hypothesized to be involved in cancer metastasis and recurrence. Over the past decade, increasing numbers of studies have been carried out to identify CSCs from human NPC cells and tissues. The present paper will summarize the investigations on nasopharyngeal CSCs, including isolation, characteristics, and therapeutic approaches. Although there are still numerous challenges to translate basic research into clinical applications, understanding the molecular details of CSCs is essential for developing effective strategies to prevent the recurrence and metastasis of NPC.
\end{abstract}

\section{Introduction}

Nasopharyngeal carcinoma (NPC) is a distinct malignancy of the nasopharynx, the uppermost region of the pharynx. NPC is highly prevalent in southern China and southeastern Asia (incidence is between 25 and 50/100,000), but is rare in the United States and most other nations (incidence $<1 / 100,000$ ) [1]. More than $90 \%$ of NPC patients are initially diagnosed as type II or type III undifferentiated and nonkeratinizing carcinoma [2]. Epstein-Barr virus (EBV)

\footnotetext{
* Correspondence: shuping@csu.edu.cn; ligy@xysm.net

tEqual contributors

${ }^{1}$ Hunan Provincial Tumor Hospital and the Affiliated Tumor Hospital of Xiangya School of Medicine, Central South University, 582 Xianjiahu Road, Changsha, Hunan 410013, China

${ }^{2}$ Cancer Research Institute of Xiangya Medical School, Central South University, 110 Xiangya Road, Changsha, Hunan 410078, China

Full list of author information is available at the end of the article
}

infection, environment and diet, and genetic factors all contribute to the development of NPC [3].

Radiotherapy or combined chemoradiotherapy shows a cure rate $>90 \%$ in patients with early-stage NPC [4], but significant rates of distant relapse and metastasis still occur in patients after radiotherapy or chemoradiotherapy. Although much progress has been gained in recent years, the 5 -year survival rate is only 50 to $60 \%$ [5]. The leading cause of mortality is attributed to local recurrence and metastasis. Although numerous molecular targeting agents have been developed due to deeper understanding of the disease progression, local recurrence still occurs in 15 to $58 \%$ [6], and the rate of nasopharynx and cervical lymph node recurrence is between 12.0 and $22.0 \%$ of patients who underwent standard chemotherapy and radiotherapy treatment during 5 years [7]. Thus it is crucial to develop effective strategies to attack cancer cells that become resistant to current chemotherapy.

In recent years, one of the major mechanisms for post-therapeutic recurrence of NPC has been suggested by the cancer stem-like cell (CSC) proposition [8-10]. According to the CSC model, cancers are hierarchically organized similar to normal tissues and cancer growth and progression are driven by a small subpopulation of tumor cells with stem cell-like properties, the CSCs. This rare cell subpopulation is responsible for tumor initiation, maintenance and regeneration. CSCs have been identified in various human malignancies such as brain cancer [11], breast cancer [12], colon cancer [13,14], pancreatic cancer $[15,16]$, and so forth.

In this paper we will summarize the studies on NPC CSCs, including isolation, characteristics, and therapeutic approaches.

\section{Experimental evidence for nasopharyngeal carcinoma cancer stem-like cells}

Recent investigations into NPC CSCs are summarized in Table 1.

\section{Biomed Central}




\begin{tabular}{|c|c|c|}
\hline Expression/functional profile & Cells/tissues studied & Characteristics of cancer stem cell identity \\
\hline Label-retaining cells & 5-8 F, 6-10B and TMNE & Increased clonogenicity, tumor formation in mice at low titers $[16,17]$ \\
\hline Label-retaining cells $\left(\mathrm{PKH} 26^{+}\right)$ & CNE1, CNE2, SUNE1, and HONE1 & $\begin{array}{l}\text { Longevity, sphere formation, side population cells, and resistance to } \\
\text { radiotherapy [18] }\end{array}$ \\
\hline Side population cells & CNE-2 & $\begin{array}{l}\text { Strong tumorigenesis ability, more resistant to chemotherapy and } \\
\text { radiotherapy, cytokine } 19 \text { positive [24] }\end{array}$ \\
\hline Side population cells $\left(\mathrm{ABCG} 2^{+}\right)$ & $5-8 \mathrm{~F}$ & $\begin{array}{l}\text { ABCG2 alone is not sufficient, PSCA, ABCG2 and ALP were expressed in } \\
\text { ABCG2 }{ }^{+} \text {cells, and K19, integrin a6, integrin } \beta 4, C D 44 \text { and } K 14 \text { were } \\
\text { expressed in } A B C G 2^{-} \text {cells [25] }\end{array}$ \\
\hline \multirow[t]{2}{*}{$\mathrm{ALDH} 1^{\text {high }}$ cells or $\mathrm{ALDH} 1 \mathrm{~A} 1$} & 5-8 $\mathrm{F}$ and $\mathrm{CNE} 2$ & $\begin{array}{l}\text { High ALDH1 activity, higher clone formation efficiency, differentiation } \\
\text { capability and higher migration, enhanced capacities of growth, } \\
\text { proliferation, and tumorigenesis, } 5 \text { to } 10^{3} \mathrm{ALDH1} 1^{\text {high }} \mathrm{NPC} \text { cells required to } \\
\text { induce tumors, vimentin } \\
\text {, and E-cadherin } \\
{\left[27,28 \mathrm{OCT} 4, \mathrm{SOX} 2 \text { and } \mathrm{Nanog}^{+}\right.}\end{array}$ \\
\hline & C666-1 & $\begin{array}{l}\text { Significantly greater ability to proliferate, be clonogenic, resist } \\
\text { chemotherapy drugs and radiation, and express pluripotent markers, } \\
\text { tumor formation at a higher rate [29-31] }\end{array}$ \\
\hline
\end{tabular}

$\begin{array}{ll}\mathrm{CD}_{4} 4^{+} & \text {5-8 F, C666-1 } \\ \mathrm{CD}_{133^{+}} & \text {CNE2 and primarily cultured NPC cells }\end{array}$

Sphere-forming cells C666-1
Higher survival rate, resist chemotherapy drugs [35,36]

$\mathrm{Nanog}^{+}$and Sox2 ${ }^{+}$, a strong potential for self-renewal, sphere formation, proliferation and differentiation and a greater potential for in vivo tumor formation in nude mice [39]

$\mathrm{CD}_{4} 4^{+}$and SOX2${ }^{+}$, higher spheroid formation efficiency, resistant to chemotherapeutic agents, CCR7 ${ }^{+}$associated recurrent disease and distant metastasis [48]

ABCG2 ATP-binding cassette sub-family G member 2; $A L D H 1$ aldehyde dehydrogenase 1; NPC nasopharyngeal carcinoma.

\section{Label-retaining cells}

Adult stem cells can be identified by the label-retaining cell (LRC) approach based on their ability to retain nucleoside analogs, such as bromodeoxyuridine. Zhang and colleagues identified LRCs from nasopharyngeal epithelia when neonatal mice were intraperitoneally injected with bromodeoxyuridine [17]. Long-term bromodeoxyuridine-labeled LRCs ( $2 \%$ of cells) were detected in the adult mice nasopharyngeal epithelia by immunostaining, and some LRCs (12\% of cells) were found to be recruited into the $S$ phase of the cell cycle with an additional radioactive thymidine-labeling technique, indicating that the stem cells also divide, most probably asymmetrically. In addition, three NPC cell lines (5-8 F, 6-10B and TMNE) were labeled with bromodeoxyuridine in vitro and then individually engrafted into the back of nude mice, where the tumors develop. Labelretaining stem cells were found in all three kinds of NPC xenograft tumors ( $0.3 \%$ of cells), around $16 \%$ of which were also labeled with radioactive thymidine. The presence of epithelial LRCs in mouse nasopharynx and human NPC tissues was demonstrated, and these stem-like LRCs are not completely quiescent as they can be recruited into the cell cycle to participate in the physiological or pathological process at any moment. Jiang and Yao also verified LRCs existing in NPC cell line 5-8 F [18]. Bromodeoxyuridine was detected in 5-8 F cells and xenograft tumors. After 8 weeks, only sporadic LRCs were detected in xenograft tumors, and these LRCs were located at the cancer margin.
The existence of LRCs in 5-8 F cells indicates the existence of cancer stem cells in NPC.

PKH26 is a lipophilic marker that intercalates into the membranes of viable cells and is not transferred between cells. A stem cell-like subpopulation $\left(\mathrm{PKH} 26^{+}\right)$was identified in NPC cell lines using a label-retention technique [19]. $\mathrm{PKH}_{26}{ }^{+}$cells were enriched for clonogenicity, sphere formation, side population (SP) cells, and resistance to radiotherapy. They also found that proto-oncogene c-MYC regulates radiotolerance through transcriptional activation of $\mathrm{CHK} 1$ and $\mathrm{CHK} 2$ checkpoint kinases by binding to the promoters using genomic approaches. Overexpression of c-MYC in the $\mathrm{PKH} 26^{+}$subpopulation leads to increased expression of $\mathrm{CHK} 1$ and $\mathrm{CHK} 2$ and subsequent activation of the DNA damage-checkpoint response, resulting in radioresistance. Furthermore, loss of CHK1 and CHK2 expression reverses radioresistance in $\mathrm{PKH}_{2} 6^{+}$cells in vitro and in vivo. This study elucidates the role of the c-MYCCHK1/CHK2 axis in regulating DNA damage-checkpoint responses and stem cell characteristics in the $\mathrm{PKH} 26^{+}$subpopulation. Furthermore, these data reveal a potential therapeutic application in NPC.

\section{Side population cells}

SP cells in tumors are a small subpopulation of cancer cells with stem-like properties that can be identified by flow cytometry analysis based on their high ability to export certain compounds such as Hoechst 33342 and 
chemotherapeutic agents. The existence of SP cells in tumors is considered a key factor contributing to drug resistance and metastasis [20-24], and presents a major challenge in cancer treatment. SP cells have been isolated from several solid tumors. NPC is characterized by lymph node of the neck and cranial nerve involvement at the early stage when the primary tumor is small or not obvious. Wang and colleagues isolated SP cells from five NPC cell lines and investigated stem cell characteristics, such as proliferation, self-renewal, and differentiation [25]. They observed a strong tumorigenic ability of SP cells following in vivo transplantation into immunodeficient mice. SP cells were found to be more resistant to chemotherapy and radiotherapy, and this was related to the ATP-binding cassette half-transporter member 2 of $\mathrm{G}$ family protein and smoothened protein expression, respectively. These data showed that SP cells in human NPC cell line CNE-2 had stem cell characteristics in vitro but also showed that they had a strong ability to form tumors in vivo.

ATP-binding cassette sub-family G member 2 (ABCG2) transports various molecules across extracellular and intracellular membranes. High ABCG2 expression subpopulation cancer cells are associated with multidrug resistance. The SP phenotype is mainly mediated by ABCG2. Zhang and colleagues isolated $\mathrm{ABCG}^{+}$ cells in 5-8 F NPC cells and compared their tumorigenic potential with $\mathrm{ABCG}^{-}$cells using the magnetic cell sorting method [26]. Cell cycle analysis indicated that $\mathrm{ABCG}^{+}$cells were mostly quiescent, and they showed lower cloning efficiency and tumorigenicity than $\mathrm{ABCG} 2^{-}$ cells. Using the Affymetrix human whole genome expression chip to identify the gene expression profile of $\mathrm{ABCG}^{+}$and $\mathrm{ABCG}^{-}$cells, both subpopulations expressed some stem cell-associated genes; for example, PSCA, ABCG2 and ALP were expressed in ABCG2 ${ }^{+}$ cells, and K19, integrin $\alpha 6$, integrin $\beta 4, \mathrm{CD} 44$ and $\mathrm{K} 14$ were expressed in $\mathrm{ABCG}^{-}$cells, suggesting there were stem cells in both $\mathrm{ABCG}^{+}$and $\mathrm{ABCG} 2^{-}$cells. This observation demonstrated that there exist $\mathrm{ABCG}_{2}{ }^{+}$cells in NPC cells, but ABCG2 alone is not sufficient for isolating cancer stem cells in 5-8 F NPC cells. Similar results have been obtained in other tumors [27]. This evidence indicates that ABCG2 alone should not be a reliable stem cell marker.

\section{ALDH $1^{\text {high }}$ cells}

Aldehyde dehydrogenase 1 (ALDH1) belongs to the aldehyde dehydrogenase superfamily, which is responsible for the oxidation of aldehydes to their corresponding carboxylic acids. ALDH1 was first used as a marker of cancer stem cells in hematopoietic cells [28]. Wu and colleagues isolated $\mathrm{ALDH}^{+}$cells from human NPC cell lines (5-8 $\mathrm{F}$ and $\mathrm{CNE} 2$ ) and found that $\mathrm{ALDH} 1^{+}$cancer cells grew faster and had higher clone formation efficiency, differentiation capability and higher migration than $\mathrm{ALDH}^{-}$cancer cells in vitro [29]. In addition, $\mathrm{ALDH}^{+}$cancer cells formed significantly more tumor spheres. In vivo experiments showed that only 5 to $10^{3}$ $\mathrm{ALDH}^{+}{ }^{+} \mathrm{NPC}$ cells were required to induce tumors. Notably, $\mathrm{ALDH}^{+}$cells were enriched in the SP and stem cell-like genes OCT4, BMI1, KLF4 and SOX2 are preferentially expressed in $\mathrm{ALDH}^{+}$cells. The expression of ALDH1 correlated significantly with TNM classification and epithelial-mesenchymal transition (EMT) markers including vimentin expression and loss of E-cadherin.

ALDH1 might be a novel stem cell marker and a valuable predictor of NPC with poor survival [30]. Yu and colleagues showed that enriched CSCs with high ALDH activity in C666-1 were associated with a significantly greater ability to proliferate, be clonogenic, resist chemotherapy drugs and radiation, reconstitute a heterogeneous population, and express pluripotent markers [31]. Two groups have investigated the expression of ALDH1A1 in NPC specimens [32,33]. Their findings indicated that increased expression of ALDH1A1 in NPC was associated with stem-like properties.

\section{$\mathrm{CD}_{4}{ }^{+}$cells}

CD44 is a cell-surface glycoprotein involved in cell-cell interactions, cell adhesion and migration. CD44 cells are reported as cell surface markers for some breast and prostate cancer stem cells [34,35]. Su and colleagues isolated $\mathrm{CD}_{4} 4^{+}$cells from NPC cell line 5-8 $\mathrm{F}$ by fluorescence-activated cell sorting [36]. CD44 was positively expressed in $52.5 \%$ of the 5-8 F cell line. Regardless of the culture conditions, with or without serum, freshly sorted CD44 cells showed stronger proliferative capacity than $\mathrm{CD}_{4} 4^{-}$and unsorted cells. The expression levels of B-lymphoma Mo-MLV insertion region 1 homolog (Bmi-1) and Oct-4 mRNA in $\mathrm{CD}_{4} 4^{+}$cells were significantly higher than for $\mathrm{CD} 44^{-}$cells. This study indicated that $\mathrm{CD} 44^{+}$cells have the biological characteristics of CSCs or cancer progenitor cells (CPCs): pluripotent marker expression, high self-renewal ability, and chemoresistance and radioresistance. Janisiewicz and colleagues reported that $\mathrm{CD} 44^{+}$cells differentiated into CD44- cells in C666 cells [37]. CD44+ cells exhibited tumor-initiating capacity in the xenograft model. Patient tumors were heterogeneous for CD44 staining, and CD44 expression is associated with clinical outcome. These observations indicated that the $\mathrm{CD} 44^{+}$subpopulation has features consistent with CSCs.

The expression of CD44 and its role as a marker of cancer stem cells in the head and neck is interesting. Recent publications have pointed out the role of CD44 as a CSC marker in the early diagnosis of head and neck 
squamous cell cancer and as a prognostic factor for relapse, recurrence of disease and chemo/radioresistance $[38,39]$. As this point, CD44 is correlated with the outcome and prognosis in head and neck squamous cell cancer and is associated with cancer stem cells if combined with other surface markers of cancer stem cells.

\section{CD133 ${ }^{+}$cells}

CD133 is a member of pentaspan transmembrane glycoproteins (5-transmembrane), which specifically localize to cellular protrusions. CD133 has been found to be expressed in hematopoietic stem cells, endothelial progenitor cells, glioblastoma, neuronal and glial stem cells and various pediatric brain tumors. A CD133 ${ }^{+}$cell population was enriched using magnetic-activated cell sorting technology in NPC cell line CNE2 by Wen's group [40]. $\mathrm{CD}_{133^{+}}$cells exhibited a stronger potential for selfrenewal, proliferation and differentiation and a greater potential for in vivo tumor formation in nude mice compared with $\mathrm{CD}_{133^{-}}$cells, although the percentage of $\mathrm{CD}_{133^{+}}$cells was small. These results suggest that CD133 may serve as a specific surface marker for nasopharyngeal cancer stem cells.

\section{Other factors}

Bmi-1 has been reported as an oncogene by regulating p16 and p19, which are cell cycle inhibitor genes. Bmi-1 is necessary for efficient self-renewing cell divisions of adult hematopoietic stem cells as well as adult peripheral and central nervous system neural stem cells. Overexpression of Bmi-1 has been found in various malignant tumors as well as in NPC [41]. Upregulation of Bmi-1 induced EMT and enhanced the motility and invasiveness of human nasopharyngeal epithelial cells, while Bmi-1 depletion enhanced the chemosensitivity of NPC cells by inducing apoptosis. Bmi-1 was therefore assumed to be a candidate cancer stem cell marker [36]. In the literature there are reports that corroborate the role of Bmi-1 as a prognostic factor for local recurrence and distant metastases in laryngeal carcinoma $[42,43]$.

\section{Sphere-forming cells}

The sphere culture assay has been used to enrich the potential CSC subpopulations when the specific CSC makers have not been defined, as is the case for most CSCs [44-48]. The character relies on their property of anchorage-independent growth in serum-free medium. Lun and colleagues reported that sphere-forming cells were isolated from an EBV-positive NPC cell line C6661 and its tumor-initiating properties were confirmed [49]. Both CD44 and SOX2 were found to be overexpressed in a majority of sphere-forming C666-1 cells. The $\mathrm{CD}_{4} 4^{+} \mathrm{SOX}_{2}{ }^{+}$cells were detected in a minor population in EBV-positive xenografts and primary tumors and were considered as potential CSCs in NPC. Notably, the isolated $\mathrm{CD}_{4} 4^{+} \mathrm{SOX}_{2}{ }^{+} \mathrm{NPC}$ cells were resistant to chemotherapeutic agents and had higher spheroid formation efficiency, showing CSC properties.

\section{Model on origin of nasopharyngeal carcinoma cancer stem-like cells}

The origin of CSCs is still controversial. Several hypotheses indicate that their origin may be heterogenic (Figure 1).

\section{Loss of differentiation of nasopharyngeal mucosa B lymphocytes or epithelial cells}

NPC is predominantly undifferentiated and nonkeratinizing. The vast majority of cases of this cancer reveal not only varying degrees of squamous differentiation, but also more or less preserved traces of the columnar cell differentiation under electron microscopy. In other words, NPC is a kind of biphasic malignant tumor with squamous differentiation with a slight advantage [50]. EBV genome analysis in the tumor cells shows that only one fusion terminal fragment exists, suggesting that viral DNA of all NPC cells is homologous and originates from the same clone proliferation [51]. Viral DNA present in the EBV-infected lymphocytes infiltrated inside the tumor can be easily traced by polymerase chain reaction amplification $[52,53]$. One may therefore suggest a hypothesis: B lymphocytes are not terminally differentiated cells or the B-cell terminal differentiation capacity can be reversed by the role of a certain factor, and then by the nasopharyngeal mucosa. B lymphocytes may be the progenitor cells of NPC. However, there is still no evidence to support this hypothesis.

EBV-encoded small RNA signals were also recently detected in the nuclei of NPC cells, and occasionally in a limited number of infiltrating lymphocytes by quantumdot fluorescent in situ hybridization [54]. In fact, the nasopharyngeal epithelial cells with some prior genetic changes are prone to transformation, and then premalignant lesions and the concurrent detection of dysplasia and invasive carcinoma of epithelial cells occur. The viral episome is maintained in the infected epithelial cell, which continues to proliferate and does not differentiate [50]. This means that the transformation of nasopharyngeal epithelial cells with genetic modifications attacked by EBV may also be the origin of NPC CSCs.

\section{Epithelial-mesenchymal transition induces cancer stem/ progenitor-like cells}

Evidence has been found that the principal oncoprotein of EBV, latent membrane protein 1 (LMP1) [55] - which is associated with human malignancies, especially NPC promotes tumor cell invasion and metastasis, as well as the EMT. Horikawa and colleagues [55] reported that 


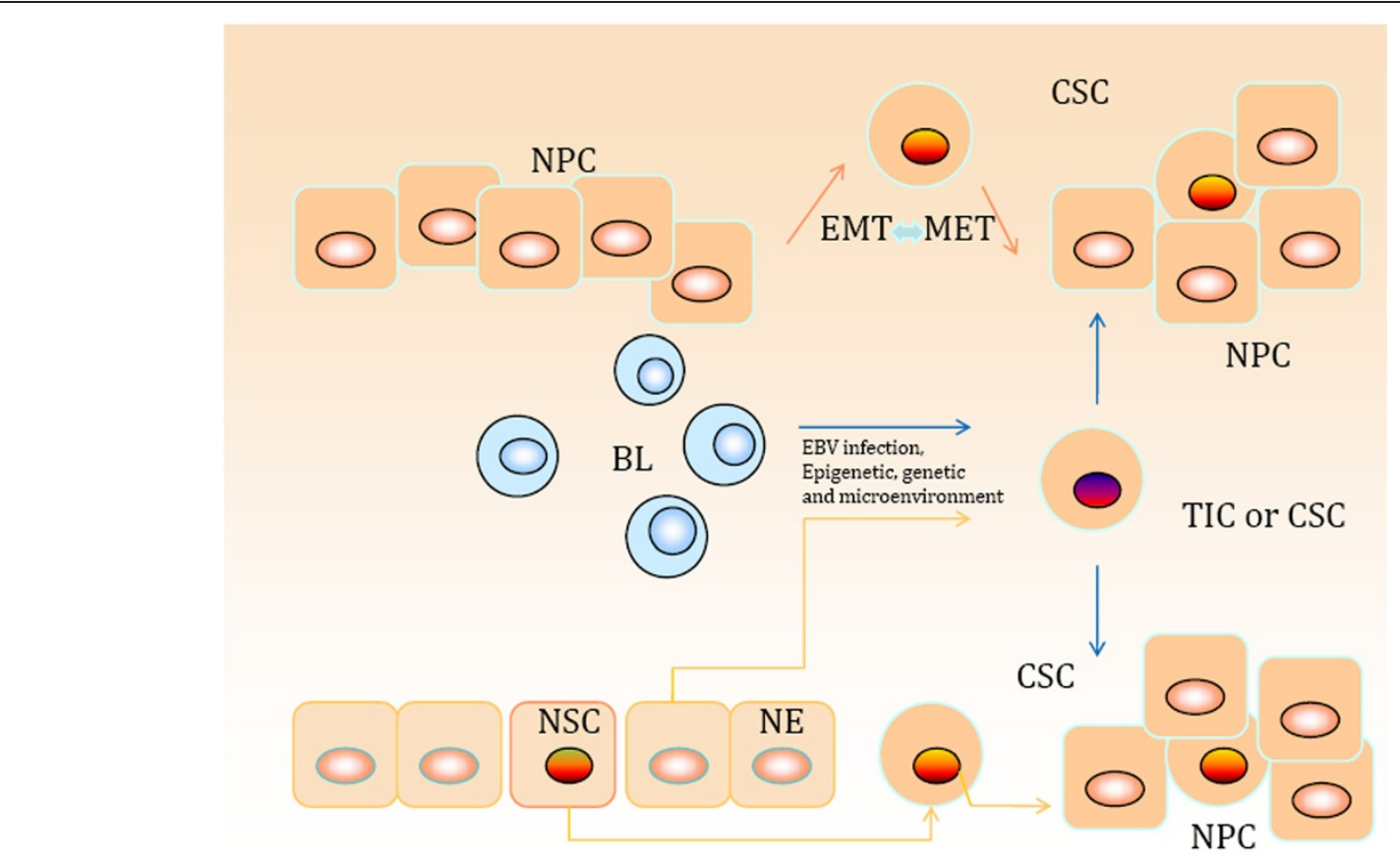

Figure 1 Model for origin of nasopharyngeal carcinoma stem or stem-like cells. BL, B lymphocytes; CSC, cancer stem-like cell; EBV, EpsteinBarr virus; EMT, epithelial-mesenchymal transition; MET, mesenchymal-epithelial transition; NE, nasopharyngeal epithelial cells; NPC, nasopharyngeal carcinoma; NSC, normal stem cell; TIC, tumor-initiating cell.

LMP1 induces the $\mathrm{CD} 44^{\text {high }} \mathrm{CD} 24^{\text {low }} \mathrm{CSC} / \mathrm{CPC}$-like phenotype as well as self-renewal abilities in LMP1expressing epithelial NPC cell lines. LMP1 increased the expression of several CPC markers as well as producing increased levels of EMT markers. These findings indicate that LMP1 can induce CPC-like properties in epithelial cells and suggest that LMP1-induced phenotypic changes contribute to the development of NPC. At the apex of the hierarchy are primitive rare CSCs, which possess extended self-renewal capabilities that allow the cells to perpetuate themselves and develop into CPCs. These CPCs have only limited self-renewal abilities and can, in turn, differentiate into various types of cancer cells. In vivo, the primitive rare CSCs rarely divide, whereas CPCs proliferate rapidly. In addition, latent membrane protein $2 \mathrm{a}$ also has similar roles in inducing EMT [56,57].

Induction of EMT in tumor cells not only promotes tumor cell invasion and metastasis, but also contributes to drug resistance [25,58-61]. These processes are consistent with the acquisition of a CSC phenotype that is also known as stemness characteristics [62]. Although CSCs may form in such a way, EMT acts as part of the process and mesenchymal cells partly have the properties of cancer stem cells.

\section{Originating from normal stem cells}

CSCs share similar properties with normal stem cells, such as a long lifespan, induction of angiogenesis, resistance to apoptosis, ability for self-renewal and differentiation, expression of stem cell markers, and so forth [46]. Normal nasopharyngeal stem reserve cells of columnar epithelium and the basal cells of squamous epithelium stem cells, especially basal cell foci of squamous metaplasia, have been considered the origin of NPC cells. Zhang and coworkers first described the identification of stem-like cells in normal mouse nasopharyngeal epithelium with the well-established LRC approach [17]. EBV infection, environment and diet, and genetic factors can promote the transformation and abnormal differentiation of normal stem cells, which may be a derivative of NPC CSCs.

\section{Therapeutic approaches targeting nasopharyngeal cancer stem-like cells}

Ongoing studies show that targeting CSCs may be a quite promising strategy. Based on the properties of NPC CSCs, many attempts have been developed to target NPC CSCs specifically (Figure 2).

Nigericin was recently reported to target CSCs selectively and to sensitize CSCs in NPC to the widely used clinical drug cisplatin both in vitro and in vivo. Nigericin decreased the SP percentages in S18 cells (higher metastatic ability) and S26 cells (much lower metastatic ability) derived from the NPC cell line CNE-2. The downregulation of the polycomb group protein Bmi-1 was found to contribute to the inhibitory effect of 


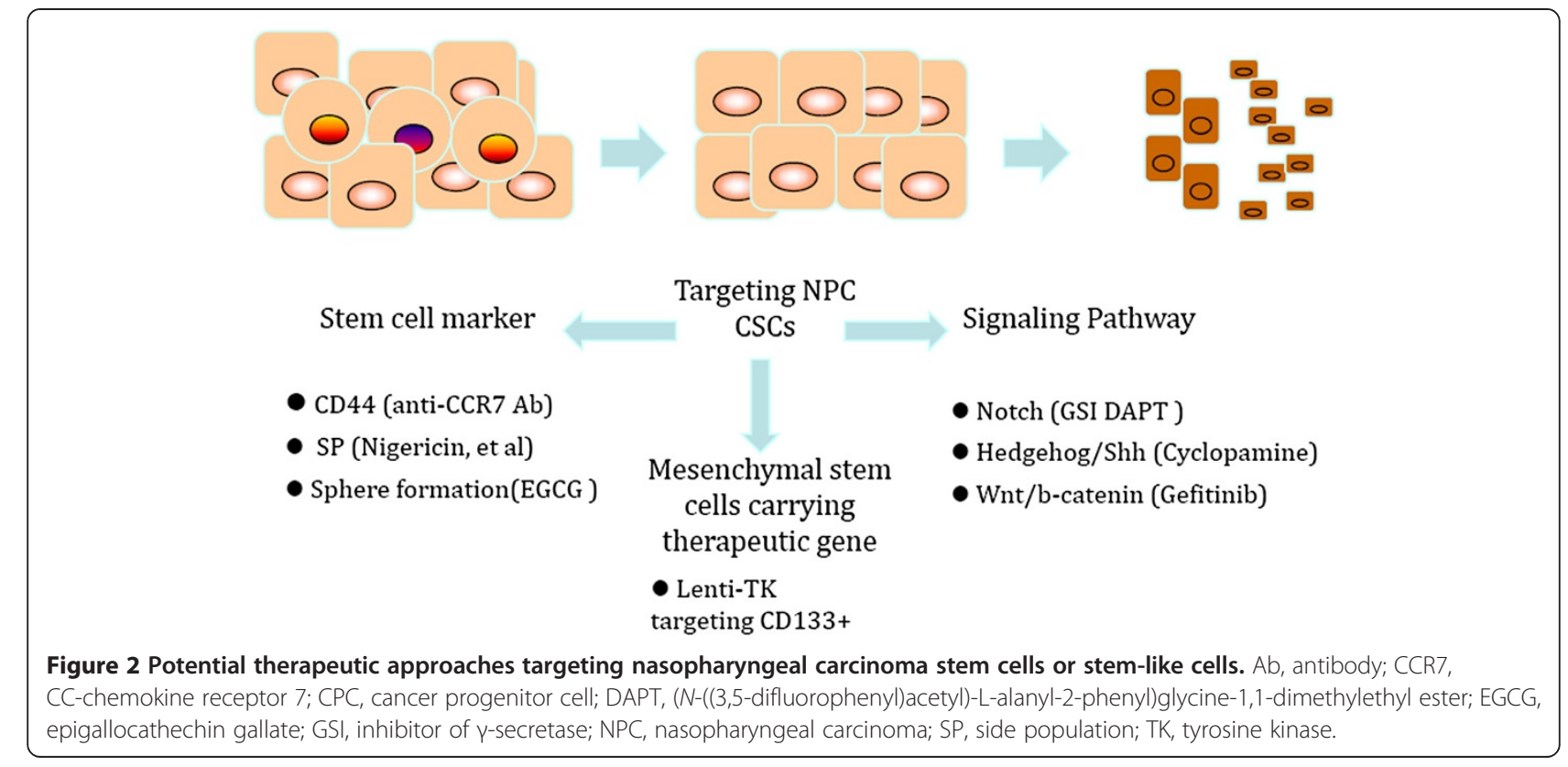

nigericin on CSCs [41]. Blocking of CCR7 with antiCCR7 antibody abolished the sphere-forming ability of C666-1 in vitro [49].

Shen and colleagues found that resveratrol impeded CSC properties through the activation of p53 and this effect could be reversed by knockdown of p53. Furthermore, resveratrol suppressed the stemness and EMT through reactivating p53 and inducing miR-145 and miR-200c, which were downregulated in NPC CSCs [63]. Epigallocathechin gallate, the most abundant catechin in green tea, has been reported to regulate NPC CSCs and their self-renewal capacity, and inhibited their invasive characteristics [64]. Smac mimetics in combination with TRAIL selectively target cancer stem cells, reduce the percentage of SP cells, inhibit colony-forming and sphere-forming abilities, and eliminate NPC stem cells in xenograft mice [65].

Notch signaling is important for the self-renewal and maintenance of stem cells. In cancer stem cells, the signaling pathway commonly is activated. $\mathrm{Yu}$ and colleagues reported that the Notch inhibitor, $(N-((3,5-$ difluorophenyl)acetyl)-L-alanyl-2-phenyl)glycine-1,1dimethylethyl ester, could reduce the proportion of SP cells from the NPC cell line CNE1,2 [66]. This ester inhibited NPC cell proliferation, depleted SP cells, reduced colony formation, and tumor formation of xenograft in immune-deficient nude mice, and induced apoptosis of NPC cells. This study shows that Notch pathway inhibition may be a promising clinical approach in CSC-targeting therapy for NPC.

The epidermal growth factor receptor pathway plays a critical role in regulating CSCs [67]. The effects of epidermal growth factor receptor on maintaining CSCs are mainly mediated by AKT signaling, and $\beta$-catenin is responsible for governing CSC properties in response to epidermal growth factor receptor/AKT activation. Tumor cells derived from cisplatin-treated mice grew rapidly, whereas regrowth of tumor cells from gefitinibtreated mice was severely diminished. Expression of epidermal growth factor receptor correlates with expression of $\beta$-catenin and nanog in primary tumor specimens from NPC patients. These findings provide mechanistic and preclinical evidence supporting the use of gefitinib alone or in combination with a chemotherapeutic agent in the therapy for patients with NPC. Targeting $\beta$-catenin is suggested to represent a rational clinical strategy for CSCs harboring activated epidermal growth factor receptor or AKT.

The hedgehog pathway, a pathway implicated in the maintenance of stem cells, is activated by the binding of a hedgehog ligand (Sonic hedgehog) to the transmembrane protein receptor Patched, releasing the inhibition of Smoothened and then activating downstream signaling components and Gli-mediated transcription of target genes. EBV activates the hedgehog signaling pathway through autocrine induction of Sonic hedgehog ligand $[68,69]$. Blocking the pathway with cyclopamine, a specific inhibitor of the Sonic hedgehog signaling pathway, reduced the proliferation of NPC epithelia cell lines and induced the apoptosis of NPC cells.

\section{Conclusion and future perspectives}

From the biological behavior of the EBV and nasopharyngeal cancer-specific cell surface markers, we hypothesized that the generation of NPC may be derived from undifferentiated clonal expansion of $\mathrm{B}$ lymphocytes or 
dedifferentiation of epithelial nasopharynx by EMT reprogramming or mutation of normal nasopharyngeal epithelial cells. These assumptions still require further experimental evidence. Similar to the heterogeneous nature of solid cancers, the origin of cancer stem cells in different individuals with the same type may vary due to epigenetic, genetic and tumor microenvironment factors.

Although many of the studies showed that these compounds have considerable promise, few provided comprehensive evidence showing that the proposed agents were specific to NPC CSCs and were considerably more effective than conventional therapy (radiation, cisplatin, and so forth). These proposed treatments still require further investigation, especially through rigorous in vivo experimentation, before they can be considered true potential CSC inhibitors and considered for use in clinical trials.

The investigations into the specific NPC CSCs and clinical therapeutic trials have been ongoing. However, there remains much to do in improving the therapeutic target specific for NPC CSCs. Several factors should be considered; first, the reliability of using cell surface markers or functional screening as a method to isolate CSCs remains controversial. Golebiewska and colleagues have reported that SP cells in human glioblastoma are non-neoplastic and are exclusively stroma derived [70]. $\mathrm{ABCG}_{2}{ }^{+}$and $\mathrm{ALDH} 1^{\text {high }}$ cannot act alone as cancer stem cells biomarkers $[26,71,72]$. A second factor is that the heterogeneous nature of NPC cells and NPC CSCs requires obtaining an individualized treatment plan. More investigations are therefore required to acquire the primary characteristics and the molecular regulation expression profile in cancer stem cells.

CSCs from various tissues appear to be more resistant to chemotherapeutic reagents than do mature cell types and characteristically express drug-resistance proteins. If this was true of NPC CSCs, therapies targeting CSCs directly should result in more reliable responses for primary as well as metastatic disease. The sensitivity of CSCs to the different strategies requires more experimental evidence confirmed both in vitro and in vivo. With these targets known, this fraction of cancer cells that can rapidly develop the critical tumor cell mass can be eliminated (Figure 2). Consequently, defining the unique properties of NPC CSCs remains a high priority for developing early diagnostic and effective therapeutic strategies against NPC.

\footnotetext{
Abbreviations

ABCG2: ATP-binding cassette sub-family G member 2; ALDH1: Aldehyde dehydrogenase 1; Bmi-1: B-lymphoma Mo-MLV insertion region 1 homolog; CPC: Cancer progenitor cell; CSC: Cancer stem-like cell; EBV: Epstein-Barr virus; EMT: Epithelial-mesenchymal transition; LMP1: Latent membrane protein 1; LRC: Label-retaining cell; NPC: Nasopharyngeal carcinoma; SP: Side population.
}

Competing interests

The authors declare that they have no competing interests.

\section{Acknowledgements}

This work was supported by the Natural Science Foundation of China (81372366, 81000972), the Foundation for the Author of Hunan Province Excellent Doctoral Dissertation of China, the Program for New Century Excellent Talents in University (NCET-12-0544), the Fundamental Research Funds for the Central Universities (2011JQ020, 2013JSJJ046), the Shenghua Yuying talents program of central South University (7601110185), and the Open-End Fund for the Valuable and Precision Instruments of Central South University.

\section{Author details}

${ }^{1}$ Hunan Provincial Tumor Hospital and the Affiliated Tumor Hospital of Xiangya School of Medicine, Central South University, 582 Xianjiahu Road, Changsha, Hunan 410013, China. ${ }^{2}$ Cancer Research Institute of Xiangya Medical School, Central South University, 110 Xiangya Road, Changsha, Hunan 410078, China. ${ }^{3}$ Guandong Provincial Yuebei People's Hospital, 133 Huimin South Road, Shaoguan, Guangdong 512025, China. ${ }^{4}$ State Key Laboratory of High Performance Complex Manufacturing, Central South University, 932 South Yeulu Mountain Road, Changsha, Hunan 410083, China.

\section{Published: 27 Mar 2014}

\section{References}

1. Lung HL, Cheung AK, Xie D, Cheng Y, Kwong FM, Murakami Y, Guan XY, Sham JS, Chua D, Protopopov Al, Zabarovsky ER, Tsao SW, Stanbridge EJ, Lung ML: TSLC1 is a tumor suppressor gene associated with metastasis in nasopharyngeal carcinoma. Cancer Res 2006, 66:9385-9392.

2. Kong L, Zhang YW, Hu CS, Guo Y: Neoadjuvant chemotherapy followed by concurrent chemoradiation for locally advanced nasopharyngeal carcinoma. Chin J Cancer 2012, 29:551-555.

3. Nor Hashim NA, Ramzi NH, Velapasamy S, Alex L, Chahil JK, Lye SH, Munretnam K, Haron MR, Ler LW: Identification of genetic and nongenetic risk factors for nasopharyngeal carcinoma in a Southeast Asian population. Asian Pac J Cancer Prev 2012, 13:6005-6010.

4. Chua DT, Sham JS, Kwong DL, Au GK: Treatment outcome after radiotherapy alone for patients with stage I-II nasopharyngeal carcinoma. Cancer 2003, 98:74-80.

5. Ma J, Mai HQ, Hong MH, Min HQ, Mao ZD, Cui NJ, Lu TX, Mo HY: Results of a prospective randomized trial comparing neoadjuvant chemotherapy plus radiotherapy with radiotherapy alone in patients with locoregionally advanced nasopharyngeal carcinoma. J Clin Oncol 2001, 19:1350-1357

6. Xu T, Tang J, Gu M, Liu L, Wei W, Yang H: Recurrent nasopharyngeal carcinoma: a clinical dilemma and challenge. Curr Oncol 2013, 20:e406e419.

7. Li JX, Lu TX, Huang Y, Han F: Clinical characteristics of recurrent nasopharyngeal carcinoma in high-incidence area. Sci World J 2012, 2012:719754.

8. Lapidot T, Sirard C, Vormoor J, Murdoch B, Hoang T, Caceres-Cortes J, Minden M, Paterson B, Caligiuri MA, Dick JE: A cell initiating human acute myeloid leukaemia after transplantation into SCID mice. Nature 1994, 367:645-648.

9. Reya T, Morrison SJ, Clarke MF, Weissman IL: Stem cells, cancer, and cancer stem cells. Nature 2001, 414:105-111.

10. Trumpp A, Wiestler OD: Mechanisms of disease: cancer stem cells targeting the evil twin. Nat Clin Pract Oncol 2008, 5:337-347.

11. Singh SK, Hawkins C, Clarke ID, Squire JA, Bayani J, Hide T, Henkelman RM, Cusimano MD, Dirks PB: Identification of human brain tumour initiating cells. Nature 2004, 432:396-401.

12. Al-Hajj M, Wicha MS, Benito-Hernandez A, Morrison SJ, Clarke MF: Prospective identification of tumorigenic breast cancer cells. Proc Natl Acad Sci U S A 2003, 100:3983-3988.

13. Dalerba P, Dylla SJ, Park IK, Liu R, Wang X, Cho RW, Hoey T, Gurney A, Huang EH, Simeone DM, Shelton AA, Parmiani G, Castelli C, Clarke MF: Phenotypic characterization of human colorectal cancer stem cells. Proc Natl Acad Sci U S A 2007, 104:10158-10163. 
14. O'Brien CA, Pollett A, Gallinger S, Dick JE: A human colon cancer cell capable of initiating tumour growth in immunodeficient mice. Nature 2007, 445:106-110

15. Hermann PC, Huber SL, Herrler T, Aicher A, Ellwart JW, Guba M, Bruns CJ, Heeschen C: Distinct populations of cancer stem cells determine tumor growth and metastatic activity in human pancreatic cancer. Cell Stem Cell 2007, 1:313-323

16. Li C, Heidt DG, Dalerba P, Burant CF, Zhang L, Adsay V, Wicha M, Clarke MF, Simeone DM: Identification of pancreatic cancer stem cells. Cancer Res 2007, 67:1030-1037.

17. Zhang HB, Ren CP, Yang XY, Wang L, Li H, Zhao M, Yang H, Yao KT: Identification of label-retaining cells in nasopharyngeal epithelia and nasopharyngeal carcinoma tissues. Histochem Cell Biol 2007, 127:347-354

18. Jiang QP, Yao KT: Isolation and detection of label-retaining cells in a nasopharyngeal carcinoma cell line. Chin J Cancer 2010, 29:572-574.

19. Wang WJ, Wu SP, Liu JB, Shi YS, Huang X, Zhang QB, Yao KT: MYC regulation of $\mathrm{CHK} 1$ and $\mathrm{CHK} 2$ promotes radioresistance in a stem celllike population of nasopharyngeal carcinoma cells. Cancer Res 2013, 73:1219-1231.

20. Zhao Y, Bao Q, Schwarz B, Zhao L, Mysliwietz J, Ellwart J, Renner A, Hirner H, Niess H, Camaj P, Angele M, Gros S, Izbicki J, Jauch KW, Nelson PJ, Bruns CJ: Stem cell-like side populations in esophageal cancer: a source of chemotherapy resistance and metastases. Stem Cells Dev 2014, 23:180-192.

21. Britton KM, Kirby JA, Lennard TW, Meeson AP: Cancer stem cells and side population cells in breast cancer and metastasis. Cancers (Basel) 2011 3:2106-2130.

22. Hosonuma S, Kobayashi Y, Kojo S, Wada H, Seino K, Kiguchi K, Ishizuka B: Clinical significance of side population in ovarian cancer cells. Hum Cell 2011, 24:9-12

23. Kabashima A, Higuchi H, Takaishi H, Matsuzaki Y, Suzuki S, Izumiya M, lizuka $H$, Sakai G, Hozawa S, Azuma T, Hibi T: Side population of pancreatic cancer cells predominates in TGF-beta-mediated epithelial to mesenchymal transition and invasion. Int J Cancer 2009, 124:2771-2779.

24. Shi GM, Xu Y, Fan J, Zhou J, Yang XR, Qiu SJ, Liao Y, Wu WZ, Ji Y, Ke AW, Ding ZB, He YZ, Wu B, Yang GH, Qin WZ, Zhang W, Zhu J, Min ZH, Wu ZQ: Identification of side population cells in human hepatocellular carcinoma cell lines with stepwise metastatic potentials. J Cancer Res Clin Oncol 2008, 134:1155-1163.

25. Wang J, Guo LP, Chen LZ, Zeng YX, Lu SH: Identification of cancer stem cell-like side population cells in human nasopharyngeal carcinoma cell line. Cancer Res 2007, 67:3716-3724.

26. Zhang H, Liu W, Feng X, Wang L, Jiang X, Liu D, Zhang L, Zhu B, Zhou W, Jia W, Li G, Ren C: Identification of ABCG2(+) cells in nasopharyngeal carcinoma cells. Oncol Rep 2012, 27:1177-1187.

27. Patrawala L, Calhoun T, Schneider-Broussard R, Zhou J, Claypool K, Tang DG: Side population is enriched in tumorigenic, stem-like cancer cells, whereas $A B C G 2^{+}$and $A B C G 2^{-}$cancer cells are similarly tumorigenic. Cancer Res 2005, 65:6207-6219.

28. Magni M, Shammah S, Schiró R, Mellado W, Dalla-Favera R, Gianni AM: Induction of cyclophosphamide-resistance by aldehyde-dehydrogenase gene transfer. Blood 1996, 87:1097-1103.

29. Wu A, Luo W, Zhang Q, Yang Z, Zhang G, Li S, Yao K: Aldehyde dehydrogenase 1, a functional marker for identifying cancer stem cells in human nasopharyngeal carcinoma. Cancer Lett 2013, 330:181-189.

30. Luo WR, Gao F, Li SY, Yao KT: Tumour budding and the expression of cancer stem cell marker aldehyde dehydrogenase 1 in nasopharyngeal carcinoma. Histopathology 2012, 61:1072-1081.

31. Yu F, Sim AC, Li C, Li Y, Zhao X, Wang DY, Loh KS: Identification of a subpopulation of nasopharyngeal carcinoma cells with cancer stem-like cell properties by high aldehyde dehydrogenase activity. Laryngoscope 2013, 123:1903-1911

32. You X, Yang YC: [Research progress of separation screening and oncogenes correlation in nasopharyngeal carcinoma cancer stem cells]. Zhonghua Er Bi Yan Hou Tou Jing Wai Ke Za Zhi 2013, 48:254-257

33. Hou W, He W, Li Y, Ma R, Wang Z, Zhu X, Fu Q, Wen Y, Li H, Wen W: Increased expression of aldehyde dehydrogenase $1 \mathrm{~A} 1$ in nasopharyngeal carcinoma is associated with enhanced invasiveness. Eur Arch Otorhinolaryngol 2014, 271:171-179.

34. Li F, Tiede B, Massagué J, Kang Y: Beyond tumorigenesis: cancer stem cells in metastasis. Cell Res 2007, 17:3-14.
35. Patrawala L, Calhoun T, Schneider-Broussard R, Li H, Bhatia B, Tang S, Reilly JG, Chandra D, Zhou J, Claypool K, Coghlan L, Tang DG: Highly purified CD44 ${ }^{+}$prostate cancer cells from xenograft human tumors are enriched in tumorigenic and metastatic progenitor cells. Oncogene 2006, 25:16961708.

36. Su J, Xu XH, Huang Q, Lu MQ, Li DJ, Xue F, Yi F, Ren JH, Wu YP: Identification of cancer stem-like $\mathrm{CD} 44^{+}$cells in human nasopharyngeal carcinoma cell line. Arch Med Res 2011, 42:15-21.

37. Janisiewicz AM, Shin JH, Murillo-Sauca O, Kwok S, Le QT, Kong C, Kaplan MJ, Sunwoo JB: CD44(+) cells have cancer stem cell-like properties in nasopharyngeal carcinoma. Int Forum Allergy Rhinol 2012, 2:465-470.

38. Allegra E, Trapasso S: Cancer stem cells in head and neck cancer. Onco Targets Ther 2012, 5:375-383.

39. Trapasso S, Allegra E: Role of CD44 as a marker of cancer stem cells in head and neck cancer. Biologics 2012, 6:379-383.

40. Zhuang HW, Mo TT, Hou WJ, Xiong GX, Zhu XL, Fu QL, Wen WP: Biological characteristics of $\mathrm{CD}_{133^{+}}$cells in nasopharyngeal carcinoma. Oncol Rep 2013, 30:57-63.

41. Deng CC, Liang Y, Wu MS, Feng FT, Hu WR, Chen LZ, Feng QS, Bei JX, Zeng $Y X$ : Nigericin selectively targets cancer stem cells in nasopharyngeal carcinoma. Int J Biochem Cell Biol 2013, 45:1997-2006.

42. Allegra E, Puzzo L, Zuccalà V, Trapasso S, Vasquez E, Garozzo A, Caltabiano $\mathrm{R}$ : Nuclear BMI-1 expression in laryngeal carcinoma correlates with lymph node pathological status. World J Surg Oncol 2012, 10:206

43. Allegra E, Caltabiano R, Amorosi A, Vasquez E, Garozzo A, Puzzo L: Expression of BMI1 and p16 in laryngeal squamous cell carcinoma. Head Neck 2012, 35:847-851.

44. Singh SK, Clarke ID, Terasaki M, Bonn VE, Hawkins C, Squire J, Dirks PB: Identification of a cancer stem cell in human brain tumors. Cancer Res 2003, 63:5821-5828

45. Fang D, Nguyen TK, Leishear K, Finko R, Kulp AN, Hotz S, Van Belle PA, Xu X, Elder DE, Herlyn M: A tumorigenic subpopulation with stem cell properties in melanomas. Cancer Res 2005, 65:9328-9337.

46. Ponti D, Costa A, Zaffaroni N, Pratesi G, Petrangolini G, Coradini D, Pilotti S, Pierotti MA, Daidone MG: Isolation and in vitro propagation of tumorigenic breast cancer cells with stem/progenitor cell properties. Cancer Res 2005, 65:5506-5511.

47. Zhang S, Balch C, Chan MW, Lai HC, Matei D, Schilder JM, Yan PS, Huang $\mathrm{TH}$, Nephew KP: Identification and characterization of ovarian cancerinitiating cells from primary human tumors. Cancer Res 2008, 68:43114320.

48. Fujii H, Honoki K, Tsujiuchi T, Kido A, Yoshitani K, Takakura Y: Sphere-forming stem-like cell populations with drug resistance in human sarcoma cell lines. Int J Oncol 2009, 34:1381-1386.

49. Lun SW, Cheung ST, Cheung PF, To KF, Woo JK, Choy KW, Chow C, Cheung CC, Chung GT, Cheng AS, Ko CW, Tsao SW, Busson P, Ng MH, Lo KW: CD44 ${ }^{+}$cancer stem-like cells in EBV-associated nasopharyngeal carcinoma. PLoS One 2012, 7:e52426

50. Raab-Traub N: Epstein-Barr virus in the pathogenesis of NPC. Semin Cancer Biol 2002, 12:431-441.

51. Pathmanathan R, Prasad U, Sadler R, Flynn K, Raab-Traub N: Clonal proliferations of cells infected with Epstein-Barr virus in preinvasive lesions related to nasopharyngeal carcinoma. N Engl J Med 1995, 333:693-698.

52. Niedobitek G, Agathanggelou A, Herbst H, Whitehead L, Wright DH, Young LS: Epstein-Barr virus (EBV) infection in infectious mononucleosis: virus latency, replication and phenotype of EBV-infected cells. J Pathol 1997, 182:151-159.

53. Niedobitek G, Agathanggelou A, Steven N, Young LS: Epstein-Barr virus (EBV) in infectious mononucleosis: detection of the virus in tonsillar B lymphocytes but not in desquamated oropharyngeal epithelial cells. Mol Pathol 2000, 53:37-42.

54. Chen HL, Peng J, Zhu XB, Gao J, Xue JL, Wang MW, Xia HS: Detection of EBV in nasopharyngeal carcinoma by quantum dot fluorescent in situ hybridization. Exp Mol Pathol 2013, 89:367-371.

55. Horikawa T, Yang J, Kondo S, Yoshizaki T, Joab I, Furukawa M, Pagano JS: Twist and epithelial-mesenchymal transition are induced by the EBV oncoprotein latent membrane protein 1 and are associated with metastatic nasopharyngeal carcinoma. Cancer Res 2007, 67:1970-1978.

56. Kong QL, Hu LJ, Cao JY, Huang YJ, Xu LH, Liang Y, Xiong D, Guan S, Guo BH, Mai HQ, Chen QY, Zhang X, Li MZ, Shao JY, Qian CN, Xia YF, Song LB, Zeng YX, Zeng MS: Epstein-Barr virus-encoded LMP2A induces an 
epithelial-mesenchymal transition and increases the number of side population stem-like cancer cells in nasopharyngeal carcinoma. PLoS Pathog 2010, 6:e1000940

57. Pegtel DM, Subramanian A, Sheen TS, Tsai CH, Golub TR, Thorley-Lawson DA: Epstein-Barr-virus-encoded LMP2A induces primary epithelial cell migration and invasion: possible role in nasopharyngeal carcinoma metastasis. J Virol 2005, 79:15430-15442.

58. Hugo H, Ackland ML, Blick T, Lawrence MG, Clements JA, Williams ED, Thompson EW: Epithelial-mesenchymal and mesenchymal-epithelial transitions in carcinoma progression. J Cell Physiol 2007, 213:374-383.

59. Sarkar FH, Li Y, Wang Z, Kong D: The role of nutraceuticals in the regulation of Wnt and Hedgehog signaling in cancer. Cancer Metastasis Rev 2010, 29:383-394.

60. Singh A, Settleman J: EMT, cancer stem cells and drug resistance: an emerging axis of evil in the war on cancer. Oncogene 2010, 29:4741-4751.

61. Wang Z, Li Y, Ahmad A, Azmi AS, Kong D, Banerjee S, Sarkar FH: Targeting miRNAs involved in cancer stem cell and EMT regulation: an emerging concept in overcoming drug resistance. Drug Resist Updat 2010, 13:109118.

62. Brabletz T, Jung A, Spaderna S, Hlubek F, Kirchner T: Opinion: migrating cancer stem cells - an integrated concept of malignant tumour progression. Nat Rev Cancer 2005, 5:744-749.

63. Shen YA, Lin CH, Chi WH, Wang CY, Hsieh YT, Wei YH, Chen YJ: Resveratrol impedes the stemness, epithelial-mesenchymal transition, and metabolic reprogramming of cancer stem cells in nasopharyngeal carcinoma through p53 activation. Evid Based Complement Alternat Med 2013, 2013:590393.

64. Lin CH, Shen YA, Hung PH, Yu YB, Chen YJ: Epigallocathechin gallate, polyphenol present in green tea, inhibits stem-like characteristics and epithelial-mesenchymal transition in nasopharyngeal cancer cell lines. BMC Complement Altern Med 2012, 12:201.

65. Wu MS, Wang GF, Zhao ZQ, Liang Y, Wang HB, Wu MY, Min P, Chen LZ, Feng QS, Bei JX, Zeng YX, Yang D: Smac mimetics in combination with TRAIL selectively target cancer stem cells in nasopharyngeal carcinoma. Mol Cancer Ther 2013, 12:1728-1737.

66. Yu S, Zhang R, Liu F, Wang H, Wu J, Wang Y: Notch inhibition suppresses nasopharyngeal carcinoma by depleting cancer stem-like side population cells. Oncol Rep 2012, 28:561-566.

67. Ma L, Zhang G, Miao XB, Deng XB, Wu Y, Liu Y, Jin ZR, Li XQ, Liu QZ, Sun $D X$, Testa JR, Yao KT, Xiao GH: Cancer stem-like cell properties are regulated by EGFR/AKT/beta-catenin signaling and preferentially inhibited by gefitinib in nasopharyngeal carcinoma. Febs $J$ 2013, 280:2027-2041.

68. Port RJ, Pinheiro-Maia S, Hu C, Arrand JR, Wei W, Young LS, Dawson CW: Epstein-Barr virus induction of the Hedgehog signalling pathway imposes a stem cell phenotype on human epithelial cells. J Pathol 2013, 231:367377.

69. Yue Y, Zhong W, Pei G, Xiao B, Zhang G, Jiang F, Zhang J, Chen C, Yang P, Dang $\mathrm{H}$, Chang $\mathrm{H}$ : Aberrant activation of Hedgehog pathway in nasopharyngeal carcinoma. Clin Exp Med 2013, 13:315-322.

70. Golebiewska A, Bougnaud S, Stieber D, Brons NH, Vallar L, Hertel F, Klink B, Schröck E, Bjerkvig R, Niclou SP: Side population in human glioblastoma is non-tumorigenic and characterizes brain endothelial cells. Brain 2013, 136:1462-1475.

71. Wang YC, Yo YT, Lee HY, Liao YP, Chao TK, Su PH, Lai HC: ALDH1-bright epithelial ovarian cancer cells are associated with CD44 expression, drug resistance, and poor clinical outcome. Am J Pathol 2012, 180:1159-1169.

72. Neumeister V, Agarwal S, Bordeaux J, Camp RL, Rimm DL: In situ identification of putative cancer stem cells by multiplexing ALDH1, CD44, and cytokeratin identifies breast cancer patients with poor prognosis. Am J Pathol 2010, 176:2131-2138.

\section{$10.1186 /$ scrt433}

Cite this article as: Wei et al:: Cancer stem-like cell: a novel target for nasopharyngeal carcinoma therapy. Stem Cell Research \& Therapy $2014,5: 44$ 